\title{
Evaluation of Student Perceptions of Sustainability in Design: A Pilot Study
}

Dr. Andrew Joseph Bechtel, The College of New Jersey

Dr. Karen Chang Yan, The College of New Jersey

Karen C. Yan is a Professor in the Mechanical Engineering Department at the College of New Jersey. Her teaching and research interests include biomaterials with tissue engineering applications, composite materials, and materials science. 


\title{
Evaluation of Student Perceptions of Sustainability in Design: A Pilot Study
}

\begin{abstract}
It has been the consensus in the engineering community that sustainability and sustainable design need to be a part of an engineer's education for last two decades. Multiple approaches have been investigated in terms of effectively integrating relevant contents and improving students' understanding. Examples include: offering technical electives (such as renewable energy, environmental impacts, etc.), establishing new concentrations focusing on sustainability issues, and integrating sustainable design throughout the curricula. However, effectively comprehending sustainable design requires understanding multiple issues from a technical, social, environmental, and economic perspective. Moreover, existing studies show that the students' background knowledge on sustainability varies widely depending on their experience and major concentration. It remains challenging to integrate the contents of sustainability and sustainable design into currently packed engineering curricula. Due to upcoming changes in The Accreditation Board for Engineering and Technology (ABET) criterion, sustainability will effectively become a measurable outcome for engineering programs seeking ABET accreditation.

This paper outlines a pilot study performed at The College of New Jersey to establish baseline data of students' perception of sustainable design at the freshman and senior levels. The study also examines effects of in-class learning activities on students' perception. Pre and post surveys were used for collecting data. The pre-exercise surveys were answered by students at both freshmen and senior levels majoring in Mechanical and Civil engineering. The results of this survey were used to establish the effects the current curriculum has on the student's conception of sustainability. They showed that there was rather small change in the student's perception comparing the freshman group and the senior group. Subsequently, in-class activities were performed with the freshman mechanical engineers and the senior civil engineers. A post survey was then administered to evaluate changes in perception. The results from the post survey showed that a single in-class activity can only generate some changes related to the discussed topics and little change in perception as whole. Systematic approaches for integrating the contents of sustainability and sustainable design are necessary to address the revised ABET criterion.
\end{abstract}




\section{Introduction}

The Accreditation Board for Engineering and Technology (ABET) is currently considering revisions to their Criterion for Accrediting Engineering Programs [1]. These changes involve a large shift in the intended scope of the criteria. Traditionally, the ABET criterion sought to ensure quality and develop engineers that satisfy the needs of constituencies [2]. The revision extends this goal to develop engineers who:

- can participate in a multicultural environment

- have discipline specific knowledge in usability, constructability, manufacturability, and sustainability

- are cognizant of the risks, uncertainties, and implications of their solutions

These ideas are not new to the ABET criterion; they were housed in Criterion 3, Outcome (c) [2]. Fortunately, they were given positions that are more prominent and established as overarching goals. In this way ABET is formally making a push to include sustainability into all engineering curricula. They further this point by the inclusion of the revised Criterion 3, Outcome 5, which states [1]:

\section{An ability to recognize ethical and professional responsibilities in engineering situations and make informed judgments, which must consider the impact of engineering solutions in global, economic, environmental, and societal contexts}

There are multiple valid definitions of sustainability that can be applied to engineering practice; in this paper, the revised Criterion 3, Outcome 5 will serves as the definition of sustainability.

In many ways using this definition of sustainability rather than the term itself elevates the ideas over the buzzword sustainability has become. Even today, the inclusion of sustainability into engineering curricula is thought of as an innovation [3]. While there are many examples of the inclusion of sustainability into different engineering curricula, including but not limited to [3-6], the practice is not yet common. However, calls for engineering education to incorporate sustainability have been happening for more than 25 years [8]. The United Nations Decade of Sustainable ended in 2014 [9]. The National Academy identified that sustainability would be one of the biggest concerns the Engineer of 2020 will have to deal with [10]. It is critical to broaden the practice of incorporating sustainability into the engineering curricula, and the changes to the ABET Criterion will bring this point to a head. While the change is critically necessary for society, the complex nature of the academic environment can make changing difficult. There are known issues with flexibility in engineering curricula. There are limits on allowable credit hours and a breadth of material, which must be covered. This flexibility can be even further limited at institutions with smaller student bodies. For instance, offering relevant electives with low enrollment leads to high operation cost, which often is not considered economically viable. In order to make effective decisions in curricular change, there must be a base understanding as to how well the current students understand the sustainability and how the current curriculum operates. 


\section{Research Questions}

This paper outlines a pilot study on student knowledge of topics in sustainability at The College of New Jersey (TCNJ). The following questions guided this study:

Question \#1: How well is sustainable engineering understood by current students, and how does it change between majors and experience levels?

Question \#2: How do in-class activities change this level of understanding?

\section{Civil and Mechanical Engineering Curricula at TCNJ}

TCNJ is a public institution located in Ewing, New Jersey. It has an approximate total enrollment of 7,400 students. Over 50 majors are supported through seven schools. The School of Engineering offers majors in Biomedical, Civil, Computer, Electrical, and Mechanical Engineering as well as Engineering Science. Currently no graduate programs in engineering are offered. The school of engineering supports approximately 600 students across all of its engineering majors. One of the focuses of the institution is small class sizes, which are ideally set at close to 25 students as possible. TCNJ operates on a course unit systems. The engineering students require waivers each term to take an overload in course units. A typical range of course load for civil and mechanical engineering students is $4.5 \sim 5.5$ course units, and a total of 39 course units is required for graduation. In addition to courses in math, science, major requirement, and liberal learning, Civil and Mechanical engineering students are required to take three upper-level technical electives. In recent years, the School of Engineering has offered a study-abroad special technical elective in sustainability. This trip is faculty led, but enrollment is limited and students must pay for the trip. It is not a viable option for every student.

\section{Methodology}

A survey was given to seniors and freshmen enrolled in the Civil and Mechanical Engineering programs. These programs were selected because they are the most traditional engineering programs offered at TCNJ, and the undergraduate curricula are well established. Both of these programs went through ABET reaccreditation in 2012. The results of the survey are intended to show how the student's ideas on sustainability change as they move through the individual curricula. Following the initial survey, a sustainability in-class activity was performed with the senior civil engineers and the freshmen mechanical engineers. After the activity, they were given a post survey to evaluate any changes in perception.

\section{Pre Survey}

The initial survey was composed of two parts. The first part (Questions 1-7) asked questions to gain an understanding of the student's perception of the term sustainability. They were asked to identify how they were introduced to the idea of sustainability and to indicate their thoughts on its level of importance to future generations, world-wide society, engineering industry, and themselves as engineers. They were asked to select the five most important aspects of 
sustainability from the following list: Communication, Consumer Behavior, Economic, Development, Education, Ecological Systems, Health, Pollution, Production, and Resource Exhaustion.

The second portion of the survey (Questions 8-14) focused on sustainability in engineering design. Question 8 asked the students to rank Economic Profitability, Social Acceptance, Manufacturing Cost, Useful life, and Disposal when developing a new product as an engineer. They were then asked to re-rank them when sustainability of the product was a high priority. Students were given three design scenarios and asked to identify which one they found to be most sustainable, and they were then prompted for a written explanation. They were then asked to give three examples of how new products impact the environment, three ways to measure environmental impact, and three examples of sustainable products or practices.

\section{Sustainability Activity and Post Survey}

\section{Civil Engineering}

After the initial survey, the senior civil engineering students were exposed to topics in sustainability through a hands-on test and a presentation in their Civil Engineering Materials and Structures course (CIV 371). As part of this course, the students make concrete. After the concrete had cured, the students performed a near surface resistivity test to evaluate the permeability of the concrete. Permeability has been linked to the durability of concrete structures, and this test is beginning to be incorporated into practice as a performance metric for concrete. The test was used as an introduction to a lecture and discussion on life-cycle cost and sustainability in civil engineering. The lecture also touched on how political lobbies influence research and civil engineering practice.

\section{Mechanical Engineering}

The freshman mechanical engineering students were from the disciplinary section of Fundamentals of Engineering Design course (ENG 142). The disciplinary part of the course focuses on the Engineering Graphics and Solid Modeling using SolidWorks. After the initial survey, the students were introduced to topics in sustainability through a presentation on lifecycle assessment (LCA) and a hands-on activity using a sustainability simulation tool. Following the SolidWorks Sustainability tutorial [11], the students modified materials assigned to a mug design. In the modifications, they also sought to reduce the total material used. The changes in design and material were examined using LCA that characterized the environmental impacts in terms of Carbon, Energy, Air and Water.

\section{Post Survey}

Following the in class activities, the two groups were asked to answer Questions 8-14 in the pre survey in addition to a question to reflect on the effects on the respective in class activities. 


\section{Results and Discussion}

Both the pre and post activity surveys were conducted in fall 2017 through Qualtrics (an electronic survey service). The surveys were anonymous, and participation was voluntary. Seventy-six students participated in the pre activity survey. There were 19 Civil engineering freshmen, 14 Mechanical engineering freshmen, 20 Civil engineering seniors, and 23 Mechanical engineering seniors. The post activity survey were sent to Mechanical Engineering freshman and Civil Engineering seniors who participated in the pre activity survey. There were four responses from Mechanical Engineering freshman and eight responses from Civil Engineering seniors.

\section{Evaluation of Research Question 1}

\section{Previous experiences (Question 1-2)}

The first survey question asked "How familiar are you with the term Sustainability?" Figure 1(a) compares the results from the freshman group and the senior group. 76\% of freshmen reported the level of familiarity as very/somewhat, $24 \%$ of freshmen reported slight and not familiar. $35 \%$ of seniors reported the level of familiarity as very, $65 \%$ of seniors reported the level of familiarity as somewhat. Comparison between the two majors shows that there is higher percent of mechanical students in the category of very familiar (Figure 1b).

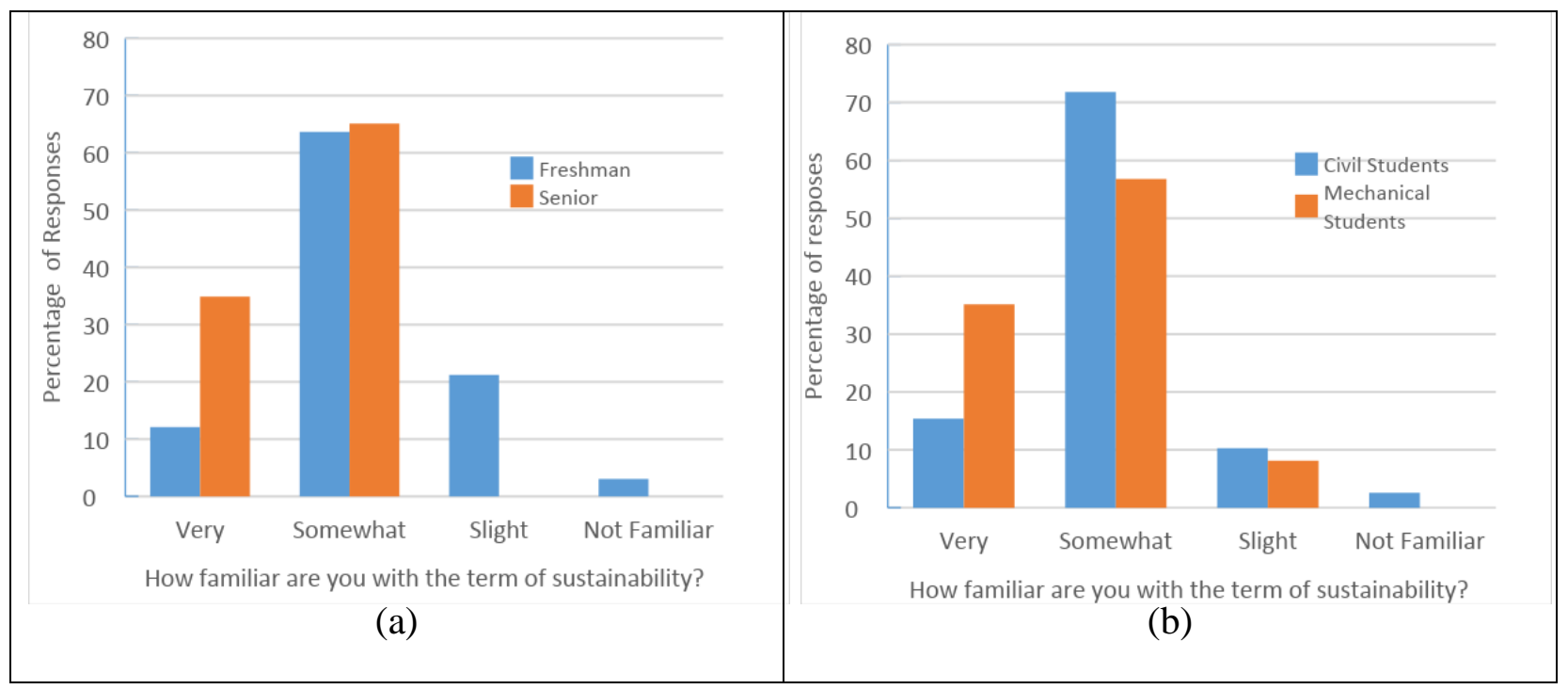

Figure 1. Survey results on how familiar students are with the term Sustainability: (a) comparison between the freshmen and the seniors, (b) comparison between the Civil engineering students and Mechanical Engineering Students

In terms of the types of previous learning sources, lectures rank the highest among the four given options, and projects rank the lowest. While the similar trends were observed in the responses from the freshman group and those from the senior group, $6 \%$ freshman and 16\% seniors selected projects. In addition, more Civil engineering students reported other activities 
contributed to their familiarity with the Sustainability. Figure 2 (a) and (b) show the survey results for this question.

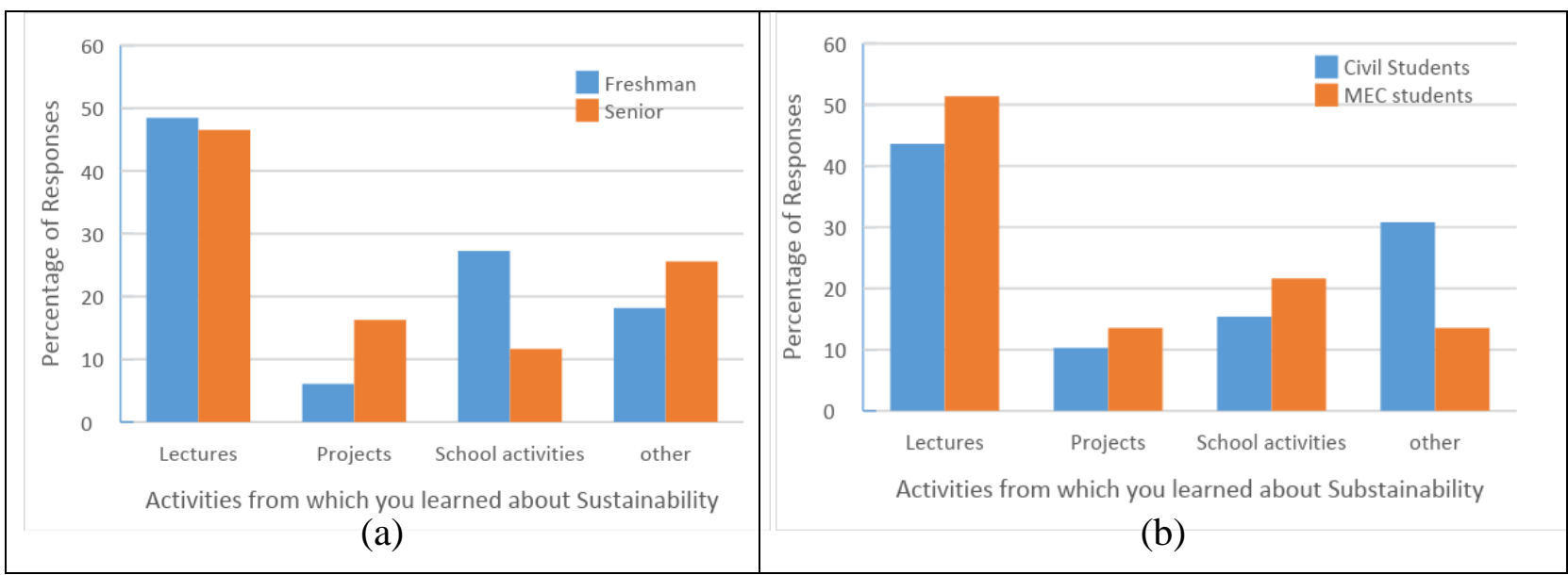

Figure 2. Survey results on types of activities: (a) comparison between the freshmen and the seniors, (b) comparison between the Civil Engineering students and Mechanical Engineering Students

Importance to future generations, society, engineering field, and engineers (Question 3-6)

Students from all groups recognized the importance of sustainability to future generations with $71 \% \sim 87 \%$ responses selecting very important. When the importance to the society is considered, almost all students selected very important/important, the percentage of selecting very important however reduced to 53\% 74\%. In the case of considering the importance of Sustainability to you as an engineer, students chose very important/important. The percentage of students choosing very important ranges from 50\% 84\% across the four groups. Question 6 asked students to rate their level of agreement with the statement "Sustainability is a key component of all engineering disciplines." All responses indicated agreement with the statement, with 30\% 63\% of responses "Strongly Agreeing" or "Agreeing" across the four groups.

\section{Aspects of Sustainability (Question 7)}

Question 7 intended to gauge the students' understanding of multi-facets nature of Sustainability. They were asked to select the five most important aspects of sustainability from the following list: Communication, Consumer Behavior, Economic Development, Education, Ecological Systems, Health, Pollution, Production, and Resource Exhaustion. The average results from all responses show that Resource Exhaustion was the most highly selected aspect and Communication was the least selected. Pollution was the second most highly selected aspect. Economic Development, Education, Ecological Systems, and Health were at a similar level. Consumer Behavior and Production were closer to the bottom. Figure 3 compares the responses from all groups. Further comparative analyses show that there were notable differences in terms of Communication, Consumer Behavior, and Ecological System between freshman and seniors, and Health between Civil and Mechanical groups (see Figure 4). 


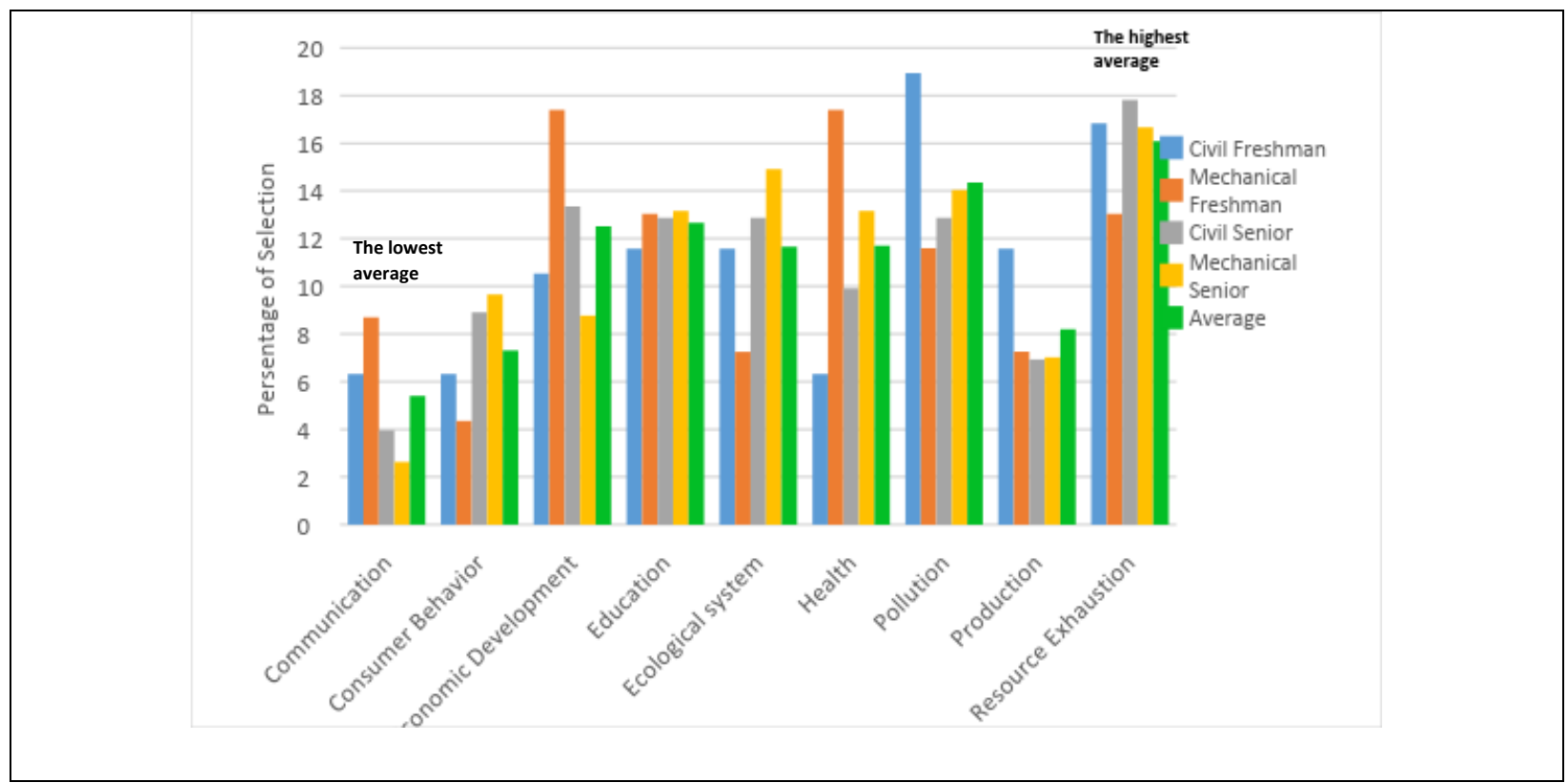

Figure 3 Survey results for selecting 5 important aspects of Sustainability

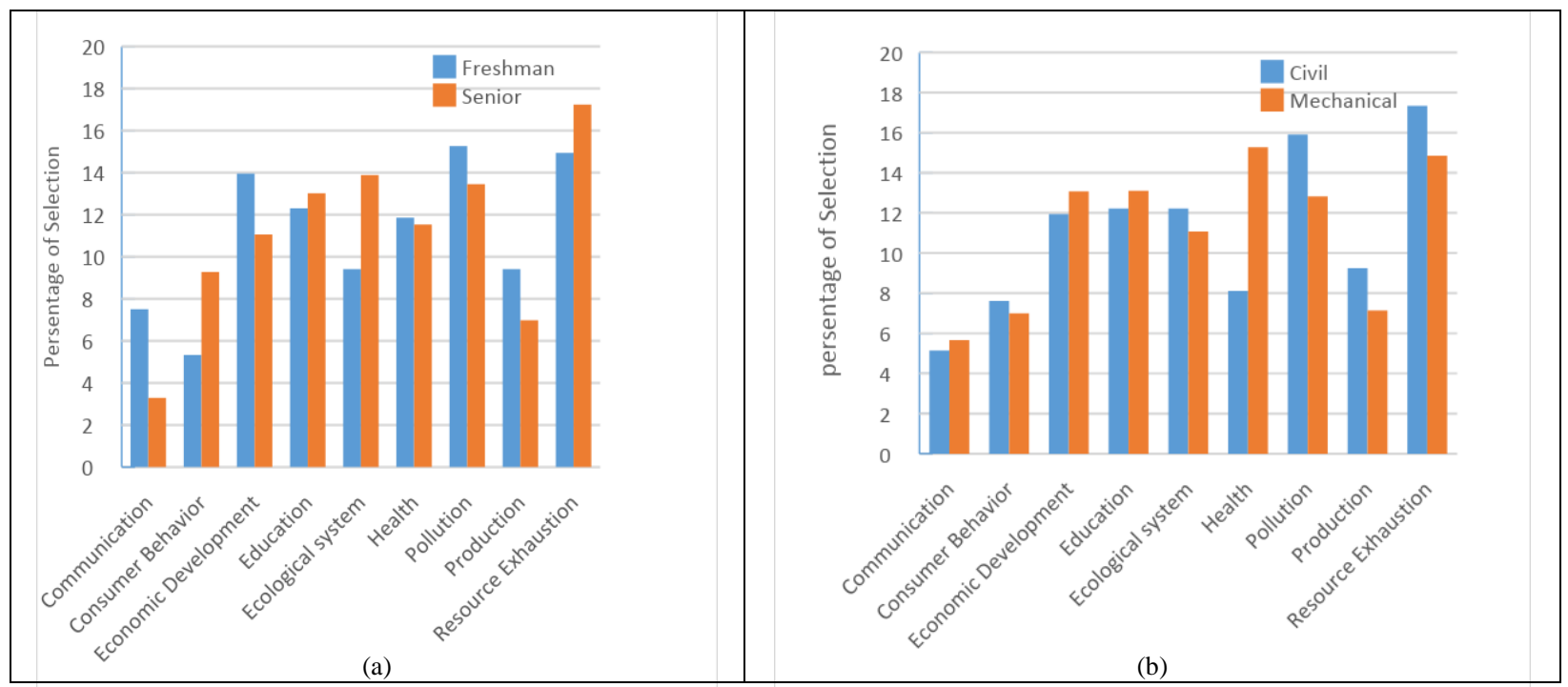

Figure 4. Survey results for selecting 5 important aspects of Sustainability: (a) comparison between the freshmen and the seniors, (b) comparison between the Civil engineering students and Mechanical Engineering Students

\section{Product Design (Questions 8-11)}

The second part of the initial survey focused on product design. Question 8 asked the students to rank Economic Profitability, Social Acceptance, Manufacturing Cost, Useful life, and Disposal when developing a new product as an engineer. They were then asked to re-rank them when sustainability of the product was a high priority (Question 9). Figure 5 (a) - (d) plot the average priority ranking for the given five aspects from all four groups. It is seen from the plots that the range of difference in average rankings changed from $0.8 \sim 1.2$ (Question 8) to 0.3 0.5 (Question 
9). This result suggested that, when the sustainability of the product was a high priority, the five aspects of product design were considered more holistically.

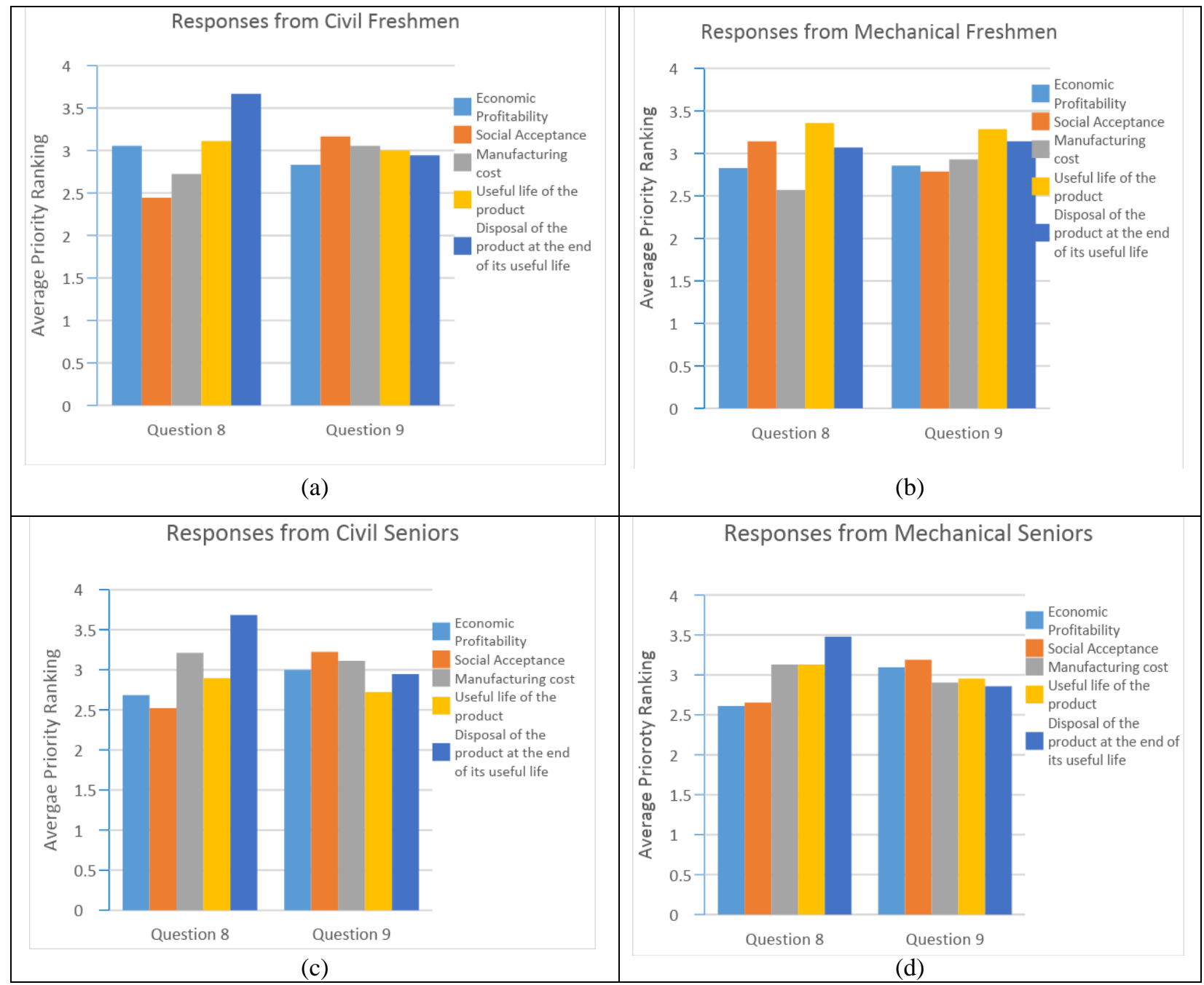

Figure 5. Average priority rankings for five aspects of product design: (a) responses from Civil freshmen, (b) responses from Mechanical freshmen, (c) responses from Civil seniors, and (d) responses from Mechanical seniors.

In Question 10, students were then given three design scenarios and asked to identify which one they found to be most sustainable, and they were then prompted for a written explanation. The three design scenarios are:

1. High profit and no consideration of environmental impacts,

2. Moderate profit and some consideration of environmental impacts

3. No profit and strong consideration of environmental impacts.

Among the freshman, 36\% chose design 2 and 64\% chose design 3. The written explanations correlated with the choices that were made. Students often equated sustainability with environmental effects alone. Among the seniors, the percentages of selecting design 1, 2 and 3 
are $7 \%, 41.5 \%$, and $51.5 \%$ respectively. The written responses made it evident that economical sustainability has been considered more by the senior group.

\section{$\underline{\text { Environmental Impacts of New Products (Questions 12-14) }}$}

In the last section of the survey, the students were asked to give three examples of how new products impact the environment, three ways to measure environmental impact, and three examples of sustainable products or practices. The written responses were grouped into ten subcategories. Figure 6 shows the distribution of responses among all groups. Pollution has the highest average rate of occurrence, and health has the lowest average rate of occurrence. When comparing the freshman and senior groups, the percentages of occurrence rate in Energy, Resource, Pollution, and Social differ by more than 5\% (see Figure 7 (a)). From the comparison between the majors, the categories with greater than 5\% difference are Energy, Social, and Economic (see Figure 7 (b)).

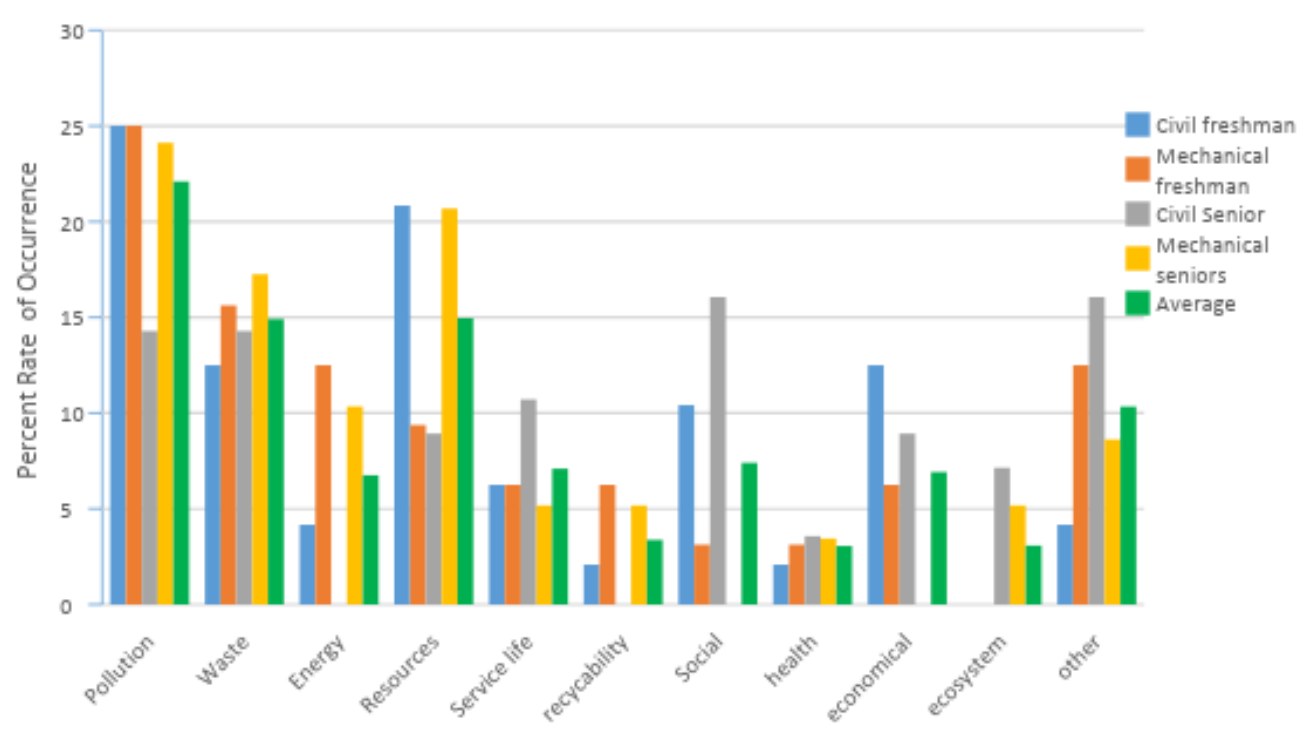

Figure 6. Occurrence rate of environmental impact examples that new products and design have 


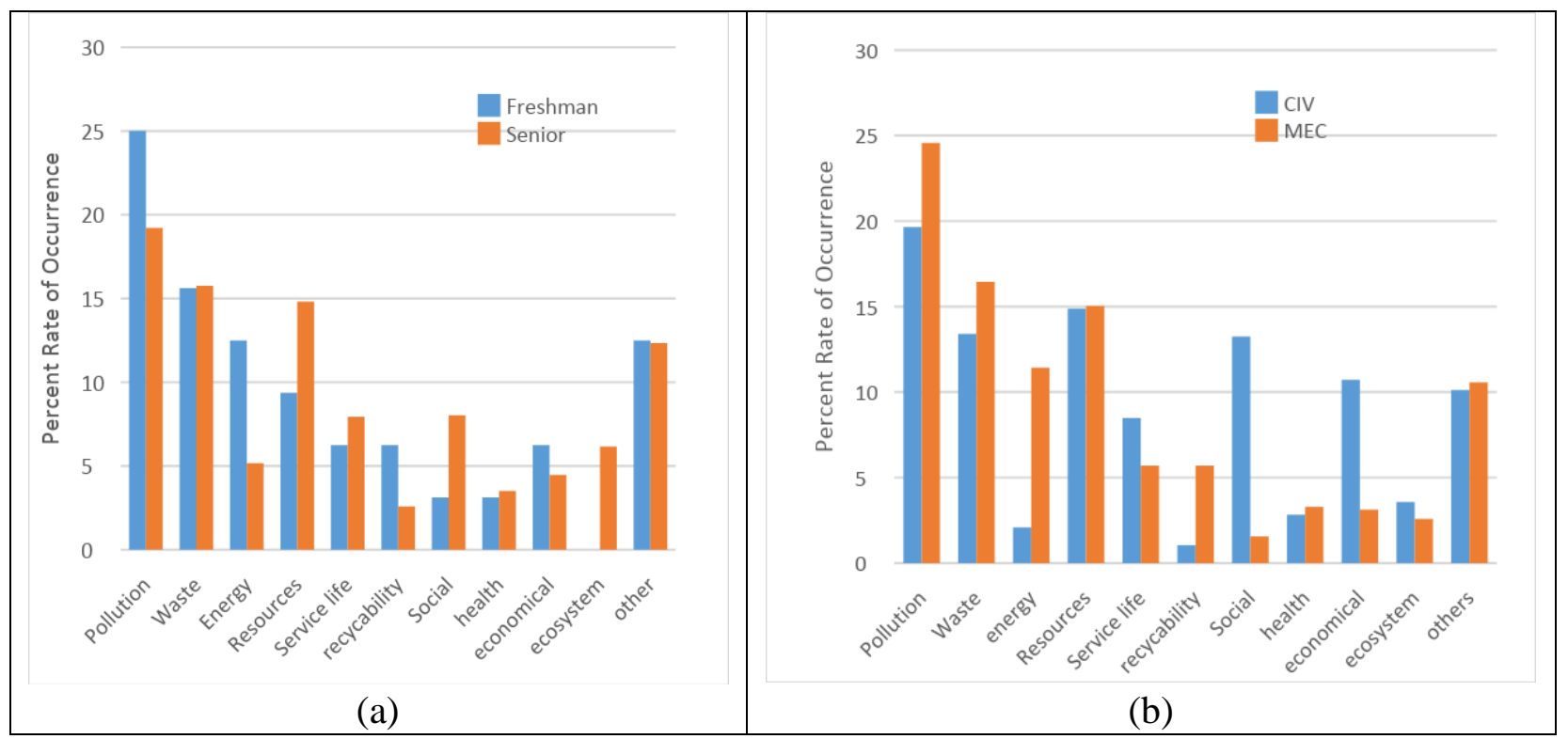

Figure 7. Occurrence rate of environmental impact examples that new products and design have: a) comparison between the freshmen and the seniors, (b) comparison between the Civil engineering students and Mechanical Engineering Students

In terms of ways to measure environmental effects, the responses follow closely with the previous question. Figure 8 presents the percent rate of occurrence from all groups. No clear difference was identified between the freshman and the senior groups as well as between the majors.

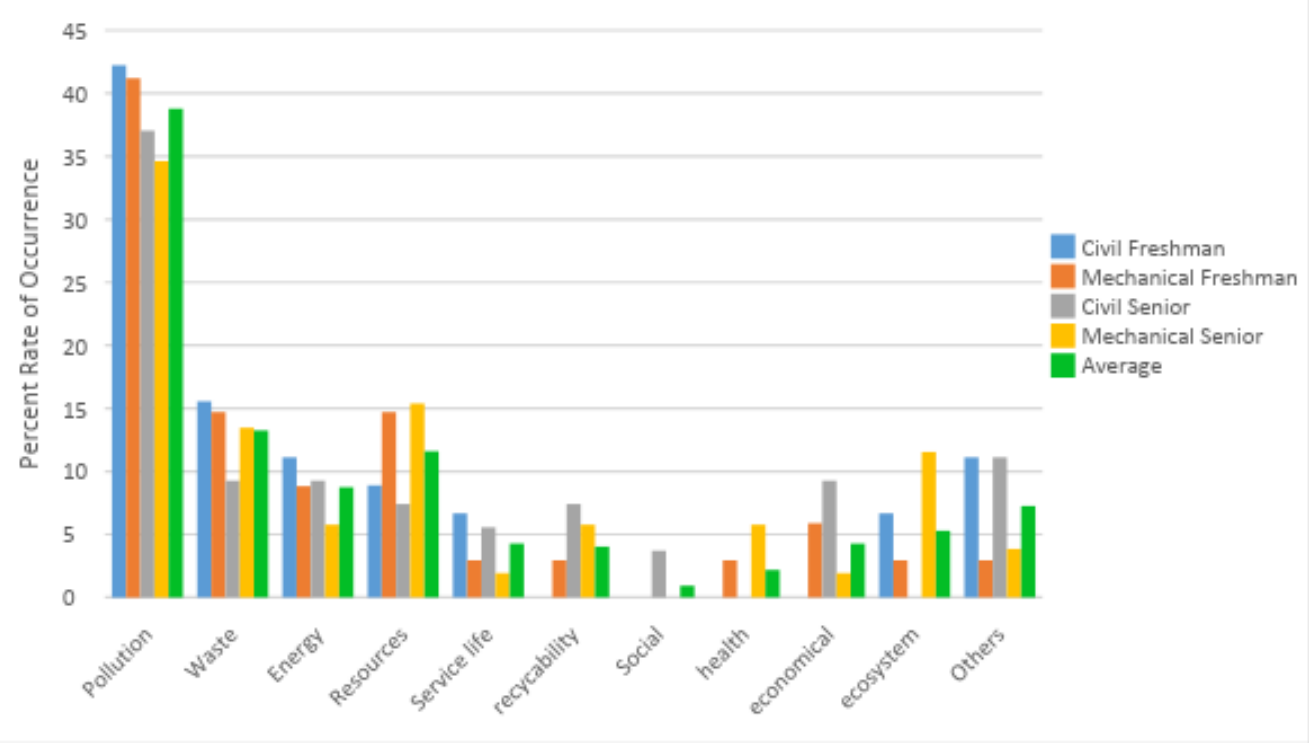

Figure 8 Occurrence rate of ways to measure environmental impact 
For the last question, examples from responses were again grouped into subcategories. Figure 9 shows the percent rate of occurrence from all groups. Renewable energy and recycling are the most frequently occurring examples of sustainable products or practices. Large differences are seen in the categories of renewable energy and recycling between the responses from freshmen and seniors (see Figure 10 (a)), and recycling and reducing between the majors (see Figure 10 (b)).

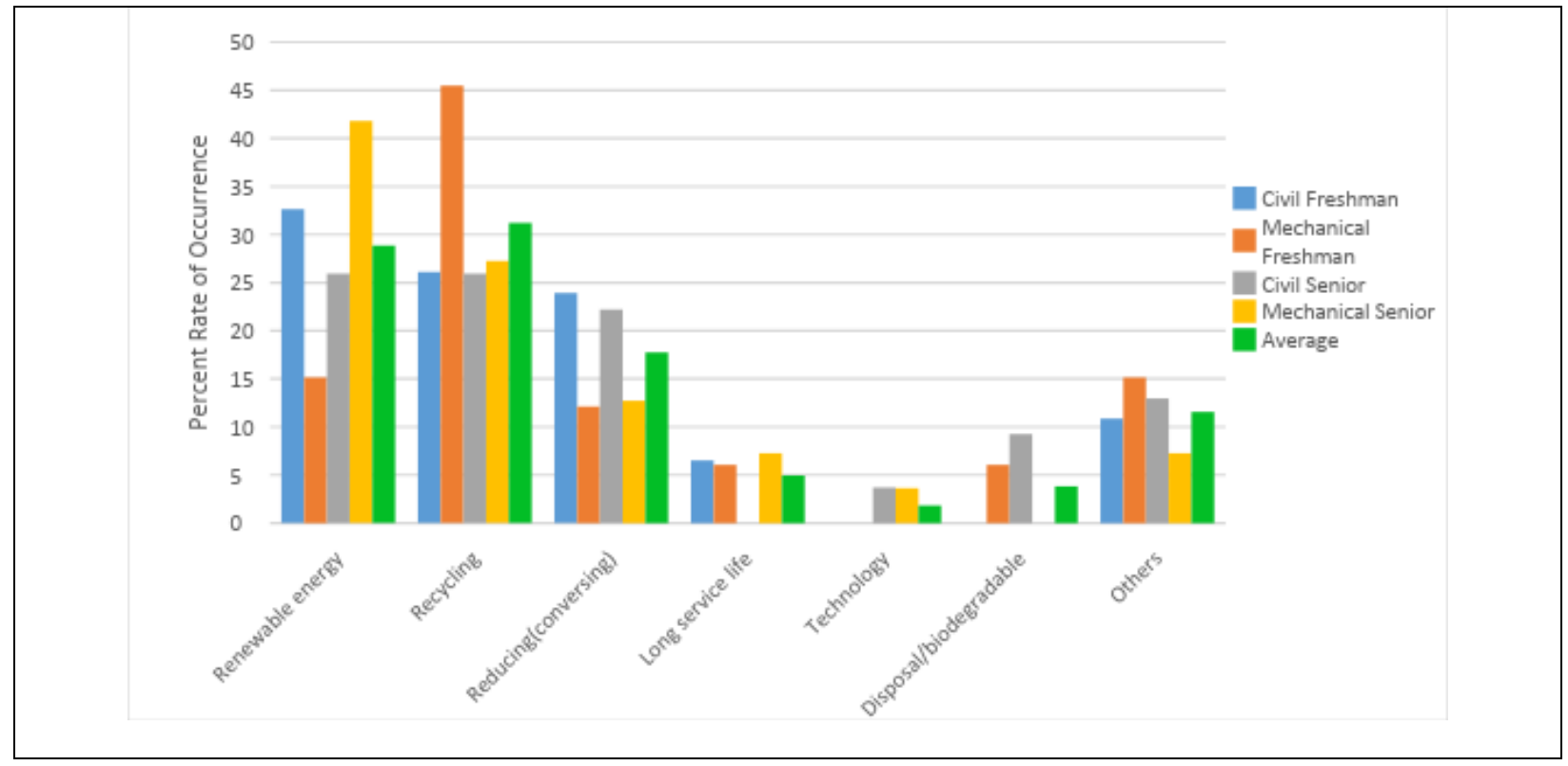

Figure 9 Occurrence rate of examples of sustainable products or practices

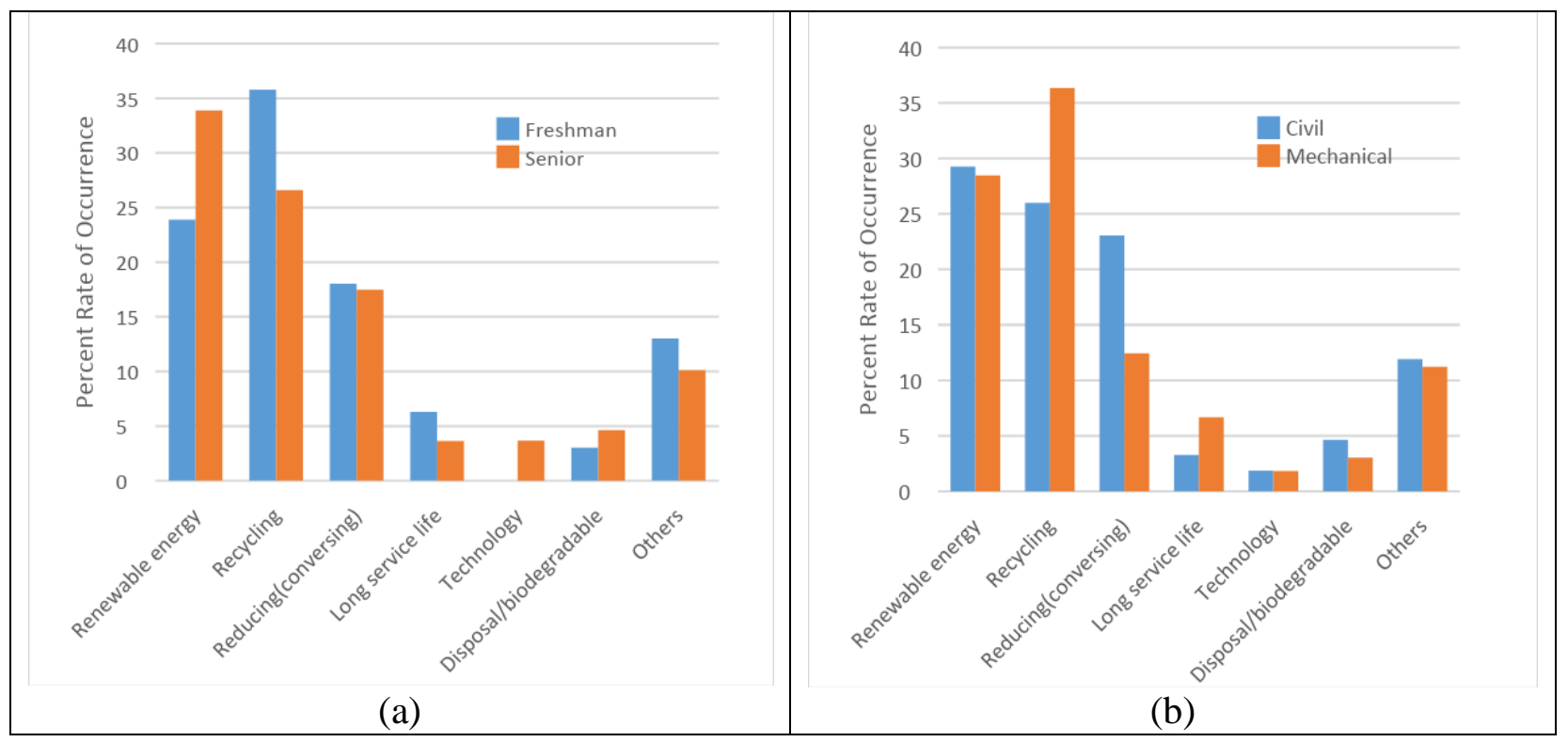

Figure 10 Occurrence rate of examples of sustainable products or practices: (a) comparison between the freshman group and the senior group and (b) comparison between the majors 


\section{Evaluation of Research Question \#2}

While the pre survey was conducted earlier in the fall semester, the post survey was conducted during the last week of class. This timing led to low participation rate for the post survey, especially from the mechanical freshman as the fall semester was the first semester in college. Analyses on the responses for Questions 8-14 after in-class activity show that there was no significant change; this result is reasonable given that each groups of students participated in a single activity. However, their written responses shed some lights on how the in-class activities affected their thought process. For example, after the LCA activities, the mechanical freshmen indicated that they had better understanding of environmental impacts of material. The Civil engineering seniors described their understanding of the multifaceted nature of Sustainability.

\section{Concluding Remarks}

In this pilot study, two surveys were conducted in order to answer two research questions. The initial survey was to collect baseline data on students' knowledge related to Sustainability and Sustainable Design. Four groups of students were selected for participation; comparative analyses were then carried out to identify the differences between the freshman and senior groups and between the students majoring in Civil and Mechanical Engineering. The responses from the freshman groups demonstrated that they are familiar with the term and recognize the importance of Sustainability, and the responses reflect that their understanding of Sustainability is highly associate with the three "R"s (Reducing, Reusing and Recycling). The responses from the senior groups also show their familiarity with the term and agreement with the importance of Sustainability. The senior groups appear to focus more on the technological development (e.g. renewable energy) and also have a more holistic view of Sustainable Design. Moreover, both groups indicated that projects were the lowest sources of learning. While it is expected that a single in-class activity did not lead to major changes in students' perception, the reflection from the students did show its positive impact. The outcomes of the current study provide a good starting point for developing systematic integration of the contents and activities in Sustainability and Sustainable Design.

\section{References}

[1] ABET. "Proposed Revisions to Criteria for Accrediting Engineering Programs Definitions, General Criterion 3: Student Outcomes, and General Criterion 5: Curriculum [Online]. Available http://www.abet.org/wp-content/uploads/2015/11/Proposed-Revisions-to-EAC-Criteria-3-and5.pdf

[2] ABET. "Criteria for Accrediting Engineering Programs [Online]. Available http://www.abet.org/wp-content/uploads/2015/10/E001-16-17-EAC-Criteria-10-20-15.pdf

[3] Lozano, Rodrigo. "Diffusion of sustainable development in universities' curricula: an empirical example from Cardiff University." Journal of Cleaner Production 18.7 (2010): 637644. 
[4] Watson, Mary Katherine, et al. "Assessing curricula contribution to sustainability more holistically: Experiences from the integration of curricula assessment and students' perceptions at the Georgia Institute of Technology." Journal of Cleaner Production 61 (2013): 106-116.

[5] Bielefeldt, Angela R. "Incorporating a sustainability module into first-year courses for civil and environmental engineering students." Journal of professional issues in engineering education and practice 137.2 (2011): 78-85.

[6] Sharma, B., et al. "Evaluation of teaching approach and student learning in a multidisciplinary sustainable engineering course." Journal of cleaner production 142 (2017): 4032-4040.

[7] Nagel, Robert L., Eric C. Pappas, and Olga Pierrakos. "On a vision to educating students in sustainability and design - The James Madison University School of Engineering approach." Sustainability 4.1 (2011): 72-91.

[8] Brown Jr, George E. "Engineers: the navigators for a sustainable future." (1993): 309-313.

[9] UN Decade of Education for Sustainable Development [Online]. Available https://en.unesco.org/themes/education-sustainable-development/what-is-esd/un-decade-of-esd

[10] Clough, G. Wayne. "The engineer of 2020: Visions of engineering in the new century." National Academy of Engineering, Washington, DC (2004).

[11] "SolidWorks Sustainable Design Guide", Dassault Systemes SolidWorks Coporation, http://www. Solidworks.com/education 